\title{
ÉTICA EM WITTGENSTEIN
}

\author{
Lucas Jairo Cervantes Bispo'; Wagner Teles de Oliveira ${ }^{2}$; \\ 1. Bolsista PROBIC/UEFS, Graduando em Filosofia, Universidade Estadual de Feira de Santana, e-mail: \\ licbispo@outlook.com \\ 2. Orientador, Departamento de Ciências Humanas e Filosofia, Universidade Estadual de Feira de Santana, e-mail: \\ woteles@gmail.com
}

PALAVRAS-CHAVE: Wittgenstein; Ética; Teoria Pictórica.

\section{INTRODUÇÃO}

O Tractatus Logico-Philosophicus, de Wittgenstein, é, mais ou menos, assimilado pela história da filosofia como responsável por ter empreendido em matéria de filosofia o que se convencionou chamar de virada linguística. Isto porque teria tornado possível a análise do pensamento a partir da proposição, a sua forma sensível. Do ponto de vista do próprio autor do Tractatus, o cerne do livre consiste na doutrina do dizer e do mostrar. Tal doutrina inscreve o Tractatus na tradição crítica, pois envolve fundamentalmente a demarcação entre o que pode ser dito e o que pode apenas ser mostrado. O espírito que move essa demarcação do campo do sentido é tramado em relação com a análise do pensamento por meio da proposição, afinal também ela só pode ser feita no âmbito da linguagem, e não do próprio pensamento. A partir da redução do dizível à forma de enunciados declarativos, o projeto do Tractatus encerra no âmbito do que não se deixa dizer todas aquelas condições lógicas que possibilitam a elaboração do discurso significativo, bem como a ética e a estética. Por visar ao absoluto, a ética não poderia ganhar corpo na forma de um discurso significativo na medida em que tudo o que se deixa dizer, porque contingente, deve poder ser negado. Com esse gesto que cria uma cisão entre o absoluto e o relativo, Wittgenstein faz ver que os domínios do significativo e do relevante não coincidem. E é exatamente por essa razão que aquelas questões que mais importam à vida, desse ponto de vista, seriam sequer tocadas caso todos os problemas científicos tivesse sido resolvidos. A não coincidência entre o significativo e o relevante articula, na verdade, a concepção pictórica da proposição que caracteriza o Tractatus. A proposição é compreendida como uma imagem de um estado de coisas ao qual ela deve identificar-se ponto a ponto, o que quer dizer que há uma relação de isomorfia entre as partes mínimas da proposição e as partes mínimas do fato do qual ela é uma imagem. Por isso mesmo, por ser figuração de um fato do mundo, a proposição só pode mesmo, a fim de lograr o propósito de representa-lo, ser essencialmente marcada pela contingência, o que quer dizer que ela deve preservar a possibilidade de ser verdadeira ou falsa. Com a distinção entre o significativo e o relevante, assim, o Tractatus parece reduzir a linguagem ao âmbito do sentido. A ética, enquanto pertencente ao domínio do que é relevante, escapa do domínio do significativo, não se deixando captar pela linguagem. Considerando isso, a pesquisa teve como objetivo examinar o lugar que o Tractatus Logico-Philosophicus, de Ludwig Wittgenstein, reserva à ética. Exame este que tentou reconstituir as exigências conceituais à luz das quais Wittgenstein separa o dizível do que não se deixa dizer, permitindo que se caracterize o primeiro como significativo e o último como relevante. Como as questões envolvidas nessa temática põe em jogo o projeto do Tractatus de demarcação do campo do sentido, a pesquisa visou à inteireza da obra, de tal sorte que as diversas passagens das quais depende a compreensão dos efeitos de uma tal demarcação foram lidas à luz de sua inspiração original. Em específico, o trabalho consistiu em confrontar o Tractatus com a "Conferência sobre Ética", interrogando-se em que medida esta apresenta um desenvolvimento das noções mais fundamentais daquele no que respeita ao plano de demarcação do sentido. 


\section{MATERIAL E MÉTODOS OU METODOLOGIA (ou equivalente)}

O método adotado consistiu na leitura e escrita de textos segundo técnicas de exegese e de escrita que caracterizam a atuação profissional na área. Assim, a execução das atividades concernidas pelo plano de trabalho privilegiou o cotejo das fontes primárias da pesquisa, sobretudo o Tractatus e a Conferência, sem se furtar à apreciação de fontes secundárias, textos de destacados comentadores, que se inscrevem na tradição de leitura da obra de Wittgenstein. Nesse sentido, o trabalho de pesquisa consistiu em duas etapas. A primeiro de leituras e fichamentos. A segunda etapa, de escrita e apresentação no Grupo de Estudo e Pesquisa para apreciação dos resultados parciais da pesquisa por meio do debate das questões que ela envolve.

\section{RESULTADOS E/OU DISCUSSÃO (ou Análise e discussão dos resultados)}

Não há no Tractatus Logico-Philosophicus uma definição do que seria propriamente a ética. Todavia, na Conferência Sobre Ética, Ludwig Wittgenstein, adota, segundo ele próprio, a definição de ética de Moore, isto é, como sendo a investigação sobre o que é bom. Num sentido mais amplo e para esclarecer-se, traz a noção de investigação sobre o valioso, o que realmente importa, o significado da vida, aquilo que faz com que a vida mereça ser vivida, ou sobre a maneira correta de viver. ${ }^{1}$ Para estudiosos como Rudolf Haller, esta compreensão está, grosso modo, em consonância com o que se denomina ética na historia da filosofia. ${ }^{2}$

Ao explicar sua concepção, Wittgenstein nos alerta para dois sentidos distintos que considera serem utilizados nas expressões, um que chama de trivial ou relativo e outro denominado ético ou absoluto, sendo apenas este segundo um juizo do qual faz uso a ética.

Nessa perspectiva, o termo "bom" em sentido trivial/relativo, nas palavras de Wittgenstein, "significa simplesmente que satisfaz um certo padrão predeterminado". ${ }^{3} \mathrm{Ou}$ seja, conforme Haller, "bom com relação a uma escala, a uma "medida previamente fixada" ou, em duas palavras, bom no contexto de um quadro de avaliação". 4

Estes juízos são, para Wittgenstein, enunciados de fatos e podem ser expressos de modo que percam toda a aparência de juízos de valor.

Tal é o convencimento de Wittgenstein que enunciados de fatos não podem ser nem implicar juízos de valor absoluto, que chega a nos dizer nesta conferência que ainda que fossemos oniscientes e escrevessemos um livro sobre tudo que sabemos, neste livro haveria uma descrição total do mundo, no entanto sequer um juízo ético. Nesse entendimento, parece estar em jogo a mesma concepção de mundo afirmada no aforisma 1 e 1.1 do Tractatus, isto é, como tudo o que é o caso, ou seja, a totalidade dos fatos.

Nesse ponto, como nos alerta Wittgenstein, poderiamos pensar que apesar de "bom" ou "mau" não serem qualidades do mundo externo a nós, são atributos de nossos estados mentais, como pode fazer crer a frase de Hamlet citada na Conferência: "Nada é bom ou mau, mas é o pensamento que o faz assim". Todavia, Wittgenstein nega esta interpretação. Alega que um estado mental entendido como um fato descritivel não é bom ou mau em sentido ético.

O que seria, então, um juízo ético/absoluto? Wittgenstein argumenta que seria um juizo que se apresentaria a nós como uma necessidade lógica, tal como seria, exemplifica, uma estrada absolutamente correta, que ao vê-la todo mundo deveria toma-la como necessidade lógica ou envergonhar-se de não faze-lo, ou o bem absoluto, que seria aquele que todo mundo, independente de seus gostos e inclinações, realizaria necessariamente ou sentiria culpa de não faze-lo. Os juizos éticos/absolutos estão, diferente dos juízos triviais/relativos,

\footnotetext{
${ }^{1}$ WITTGENSTEIN, Conferência sobre Ética, p. 216.

${ }^{2}$ HALLER, A Ética no Pensamento de Wittgenstein, p. 45.

${ }^{3}$ WITTGENSTEIN, Conferência sobre Ética, p. 217.

${ }^{4}$ HALLER, A Ética no Pensamento de Wittgenstein, p. 46.
} 
isentos de conteúdo fático, por outro lado os juízos triviais/relativos, que possuem conteúdo fácito mas não são juizos de valor, não tem o poder coercitivo que Wittgenstein defende ser próprio de um juizo ético/absoluto.

Essa compreensão pode ser entendida como em concordância e desenvolvendo ao menos duas passagens do Tractatus: o aforisma 6.375 e o 6.4. No primeiro Wittgenstein afirma só existir necessidade na lógica (e não em juizos éticos, como procura mostrar na Conferência). No segundo, alega que todas as proposições tem igual valor. Para Margutti, se este 'valor' quer dizer 'valor ético', este aforismo poderia ser refraseado nos seguintes termos: "todas as proposições são de igual valor porque não possuem qualquer valor". 5

Essa distinção entre juizos relativos e absolutos, e a indescritibilidade desses últimos, não se encontra no Tractatus, mas podemos interpretá-la como um desenvolvimento do que seria um direcionamento já presente nessa primeira obra. Isto porque, no aforisma 6.41, Wittgenstein afirma que não há valores no mundo, que nesse só há fatos e portanto contingência, e que se há valores estes devem estar fora do mundo. Já no aforisma 6.42 declara a impossibilidade de proposições éticas. A plausabilidade dessa interpretação consiste no fato do Tractatus e a Conferência concordarem que não há valores no mundo, que se existem, existem somente fora desses, também como, por isso (por não serem fatos no mundo), não podem ser expressos. Os juizos relativos, com aparência de juizos éticos, apresentados na Conferência se refeririam a estes fatos contingentes, já os juizos absolutos a estes valores fora da contingência, ou seja, fora do mundo.

Nesse sentido, Wittgenstein, considerando que o uso que fazemos das palavras em ciência são recipientes capazes apenas de conter e transmitir significados e sentidos naturais, afirma que a Ética, se é algo, é sobrenatural e nossas palavras apenas expressam fatos, e quanto a estes e as proposições só existiriam valores relativos. Ou seja, nas palavras do autor: "A Ética, na medida em que brota do desejo de dizer algo sobre o sentido último da vida, sobre o bem absoluto, o absolutamente valioso, não pode ser uma ciência."6. Esse convencimento já se mostra presente no Tractatus, quando no aforisma 6.52 afirma que "mesmo que todas as questões científicas possíveis tenham obtido resposta, nossos problemas de vida não terão sido sequer tocados".

Ainda na tentativa de esclarecer o que seria um juizo absoluto e o que teriamos em mente quando usamos expressões como "bem absoluto", "valor absoluto" e etc., Wittgenstein recorre a exemplos pessoais a partir dos quais cada um poderia invocar experiencias próprias identicas ou semelhantes. Os exemplos são três experiências, das quais interessa mais ao presente texto as seguintes: a de assombrar-se diante da existência do mundo e a de sentir-se absolutamente seguro. Cada uma destas experiências, dirá Wittgenstein, ainda que experiênciadas por ele como absolutas, carecem de sentido ao serem expressadas dessa forma.

Tendo em vista estas experiências, Wittgenstein, considerando esse problema da ausência de conteúdo fático nas expressões éticas, nos diz que a linguagem ética parece constantemente usar smiles. Um smile pode ser entendido como uma expressão que serve de auxilio para esclarecer o sentido do que queremos dizer. Todavia, segundo o autor, se podemos descrever um fato através de um smile, poderiamos também abandona-lo e descrever o fato diretamente, mas ao tentarmos fazer isso com a linguagem ética, deparamonos com a ausência de tais fatos. Desse modo, aquilo que, num primeiro momento, pareceu ser um smíle, revela-se como um mero sem sentido.

Não se trata, portanto, como Wittgenstein afirmará no fim da Conferência, dessas expressões carentes de sentido não possuirem sentido por ainda não terem sido expressas corretamente, mas sim que esta falta de sentido constitui sua própria essência.

\footnotetext{
${ }^{5}$ MARGUTTI, Iniciação ao Silêncio, p. 235.

${ }^{6}$ WITTGENSTEIN, Conferência sobre Ética, p. 224.
} 


\section{CONSIDERAÇÕES FINAIS (ou Conclusão)}

Ao compreendermos a Conferência Sobre Ética como uma extensão do Tractatus Logico-Philosophicus, essa se revela um texto que reforça, esclarece e desenvolve as noções mais fundamentais desse outro quanto a delimitação do que pode ou não ser expresso com sentido pela linguagem, acerca do que seria a ética e quais expressões tem carater ético ou não. Ética que por sua vez, tanto no Tractatus como na Conferência, está fora do ambito do dizivel, dado que não satisfaz as condições já expostas para que pudesse ser dita com sentido.

\section{REFERÊNCIAS}

DALL'AGNOL, Darlei. Ética e Linguagem: uma introdução ao Tractatus de Wittgenstein. Sâo Leopoldo. Editora Unisinos, 2005. p. 213-224.

GLOCK, Hans-Johann. Dicionario Wittgenstein. Rio de Janeiro: Jorge Zahar, 1998.

MORENO, Arley R. Wittgenstein: os labirintos da linguagem: ensaio introdutório. São Paulo: Moderna, 2000.

PINTO, Paulo Roberto Margutti. Iniciação ao silêncio: análise do Tractatus de Wittgenstein. São Paulo: edições Loyola (coleção Filosofia), 1998.

SANTOS, Luiz Henrique Lopes dos. “A Essência da Proposição e a Essência do Mundo”. In: Tractatus Logico-Philosophicus, Edusp, São Paulo, 2008.

WITTGENSTEIN, Ludwig. Tractatus LogicoPhilosophicus. 3.ed. 2.reimp. São Paulo: EDUSP, 2010.

“Conferêcia sobre Ética”. In: DALL’AGNOL, Darlei. Etica e Linguagem: uma introdução ao Tractatus de Wittgenstein. Sâo Leopoldo. Editora Unisinos, 2005. p. 213-224.

HALLER, R. A Ética no pensamento de Wittgenstein. São Paulo, Revista Estudos Avançados, v. 5, n. 11, 1991. 